\title{
Static perimetry in the study of amblyopic scotomata
}

\author{
D. P. AGGARWAL AND GOPAL VERMA \\ From the Department of Ophthalmology, University College of Medical Sciences, \\ and Safdarjang Hospital, New Delhi, India
}

SUMMARY A visual field study of 50 cases of unilateral functional amblyopia revealed a relative central scotoma of $2-10^{\circ}$ width and $0 \cdot 1$ to $0.8 \mathrm{LU}$ (log units of neutral density filters) depth in 29 out of 50 cases by static perimetry, while kinetic perimetry revealed a central scotoma in only 3 cases of paramacular fixation. In the majority of cases the eccentric area of fixation lay on the edge of the amblyopic scotoma, and it was identical to the point of peak retinal sensitivity.

The consensus of opinion is that reduction of foveal function by a suppression scotoma influences the development of fixation anomalies in amblyopic eyes. Amblyopic scotomata have been studied by several workers using different perimetric techniques, but the results are not in agreement, and the development of central inhibitory scotomata is also disputed. Thus Cuppers ${ }^{1}$ considers the development of amblyopic scotomata to be a pathological exaggeration of local adaptation (Troxler's phenomenon) based on field charting studies of amblyopic patients by static perimetry, and he found that the sensitivities obtained by static perimetry were inferior to those obtained by kinetic perimetry. Cuppers's view was supported also by Francois et al. ${ }^{2}$ On the other hand Mackensen, ${ }^{3}$ using the static perimetry technique, proved that in eccentrically fixing eyes the scotoma is deepest at the level of the abnormal fixating point, where sensitivity is inferior to that of fovea fixation point. He found static perimetry to be superior to other methods of visual field charting in amblyopic patients.

The present study was undertaken to compare the results of static and kinetic field charting in amblyopic patients and also to compare the retinal light threshold values in the area of eccentric fixation and in the region of foveal fixation of the same eye by means of static perimetry.

\section{Material and methods}

Fifty patients with unilateral functional amblyopic and visual loss of more than 2 lines as compared with the fellow eye (i.e., 6/12 or below with full refractive correction and no detectable fundus

Correspondence to Professor D. P. Aggarwal. pathology) were selected from the Amblyopia and Squint Clinic of the Ophthalmic Department, Irwin Hospital, New Delhi.

The age of the patients ranged from 7 to 35 years. In all cases selected for study a detailed history regarding age of onset of amblyopia or squint, nature of deviation, and any previous treatment in the form of glasses, orthoptics, pleoptics, or surgery was recorded. In all cases after retinoscopy and fundus examination under appropriate cycloplegia glasses were prescribed and visual acuity determined by Snellen's optotypes. The type of fixation pattern and degree of eccentricity were determined in all cases by the graticule incorporated in Heine's ophthalmoscope. Only cases of central fixation and cases with steady eccentric fixation were selected for field charting. Field examination was done with a white target size II $\left(1 \mathrm{~mm}^{2}\right)$, luminosity 4 , on Goldmann's perimeter. Static perimetry technique was employed for the amblyopic as well as for the normal eye on Goldmann's perimeter with a static attachment using target size II and a background illumination $31 \cdot 5$ apostilb.

The target was presented thrice for 1 second at intervals of 3 seconds in order to avoid local adaptation (Troxler's phenomenon). The meridian which we had examined by static perimetry technique passed through the foveal fixation point of the amblyopic eye and the eccentric area of fixation in cases of eccentric fixation, whereas in cases of central fixation the meridian passed through the foveal point on the $0-180^{\circ}$ axis. The target luminosity was recorded on the $0^{\circ}$ meridian, and this luminosity was the light threshold of the foveal fixation point or the eccentric area of fixation, depending on whether the patient had foveal or eccentric fixation. The differential light threshold for a white target 
size II was thus recorded for the following points $0,1,2,3,5,10,15,20,25,30,40,50^{\circ}$. The borders of the blind spot and the scotomata were examined degree by degree. The width of the scotomata was measured in degrees from one edge of the crater to the other on the horizontal diameter. The depth of the scotoma was measured in terms of log units of neutral density filters (LU).

\section{Results}

AMBLYOPIA WITH FOVEAL FIXATION

In all 25 cases of central fixation a routine monocular kinetic central field charting failed to reveal any defect.

The static perimetry technique revealed a definite lowering of the light threshold curve in the amblyopic eye as compared to normal eye, with marked depression of retinal sensitivity at the fovea of the amblyopic eye in all cases. The depression of retinal sensitivity was directly proportional to depth of the amblyopia (Fig. 1).

A central relative scotoma of $2-8^{\circ}$ was detected in 11 out of 25 cases $(44 \%)$.

The depth of the scotoma varied from $0 \cdot 1$ to $0 \cdot 8$ LU. The central relative scotoma was deepest at the position of foveal fixation in the majority of cases (Fig. 2).

\section{AMBLYOPIA WITH ECCENTRIC FIXATION}

A routine kinetic central field charting revealed a relative scotoma of $3-4^{\circ}$ within an area of $5^{\circ}$ around the foveal fixation point in only 3 of 25 cases $(12 \%)$.

Static perimetry technique showed scotoma of $2-10^{\circ}$ in 18 out of 25 cases $(72 \%)$ inclusive of 3 cases detected by kinetic perimetry (Fig. 3).

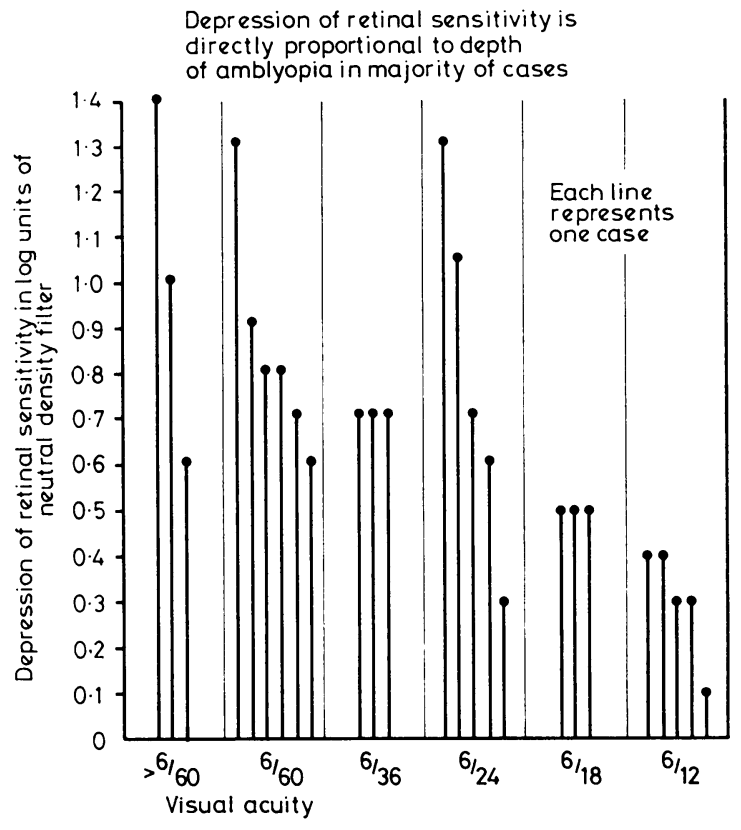

Fig. 1 Relation between depth of amblyopia and depression of retinal sensitivity in static perimetry.

In 13 out of 18 cases $(72 \cdot 2 \%)$ which showed scotomata the point of eccentric fixation was lying on the edge of the scotoma. In 16 out of 25 cases $(64 \%)$ the sensitivity of eccentric point chosen for fixation by the amblyopic eye was higher than that of the foveal fixation point of the same eye. In 7 cases $(28 \%)$ the fovea of the amblyopic eye was more sensitive than the eccentric area of fixation and had predominance over all other retinal points. Only in 2 cases $(8 \%$ ) was the peak of retinal sensi-
Fig. 2 Static perimetry chart of an amblyopic patient (fixation-foveal) showing depth of scotoma $0 \cdot 2 \mathrm{LU}$ and width of scotoma $4^{\circ}$ ( $L U=$ long units of neutral density filter). 


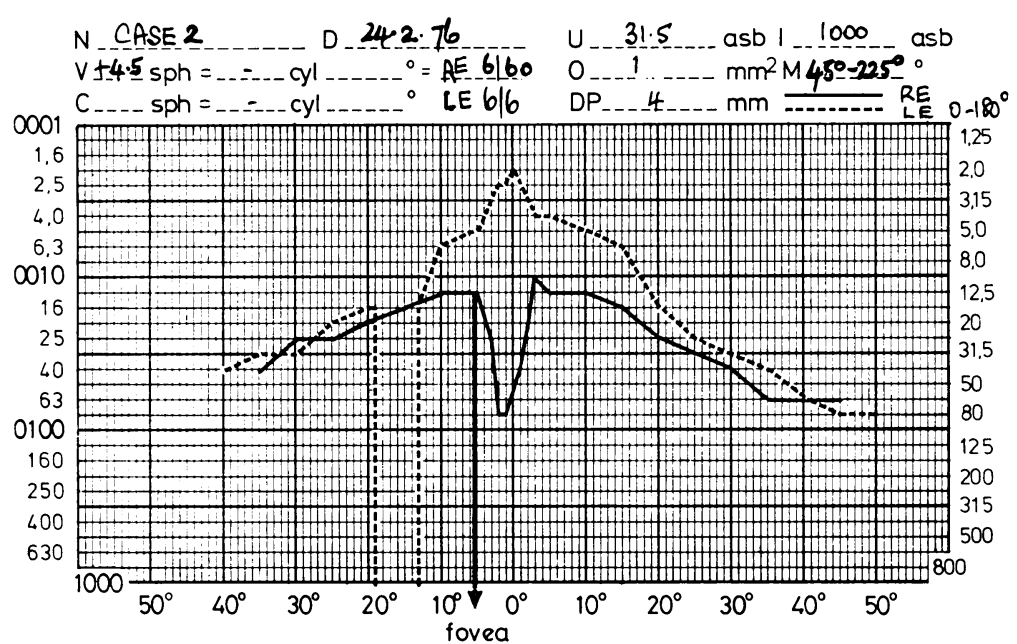

Fig. 3 Static perimetry chart of an amblyopic patient having paramacular fixation. Depth of scotoma $0 \cdot 8 \mathrm{LU}$ and width of scotoma $8^{\circ}$. tivity of the eccentric point of fixation equal to the foveal point of fixation of the amblyopic eye (Fig. 4).

\section{Discussion}

The pattern of central visual loss in amblyopia ex-anopsia has been studied by Mackensen. ${ }^{3} \mathrm{He}$ has shown a very slight central relative scotoma of only $2-4^{\circ}$ in diameter under monocular testing with normal sensitivity levels elsewhere. The area of eccentric fixation could not be identical with the area of highest light sensitivity, that is, the peak of retinal sensitivity did not coincide with the point of eccentric fixation.

A similar study was done by Blatt and Regenbogen. ${ }^{4}$ These authors found a complete scotoma to white and to colours corresponding to the macula in all cases of eccentric fixation using monocular scotometry. Other authors, such as Pasino and Mariani, ${ }^{5}$ claim that a central scotoma is present in only a few cases and then almost uniquely in marked strabismic amblyopia with eccentric fixation

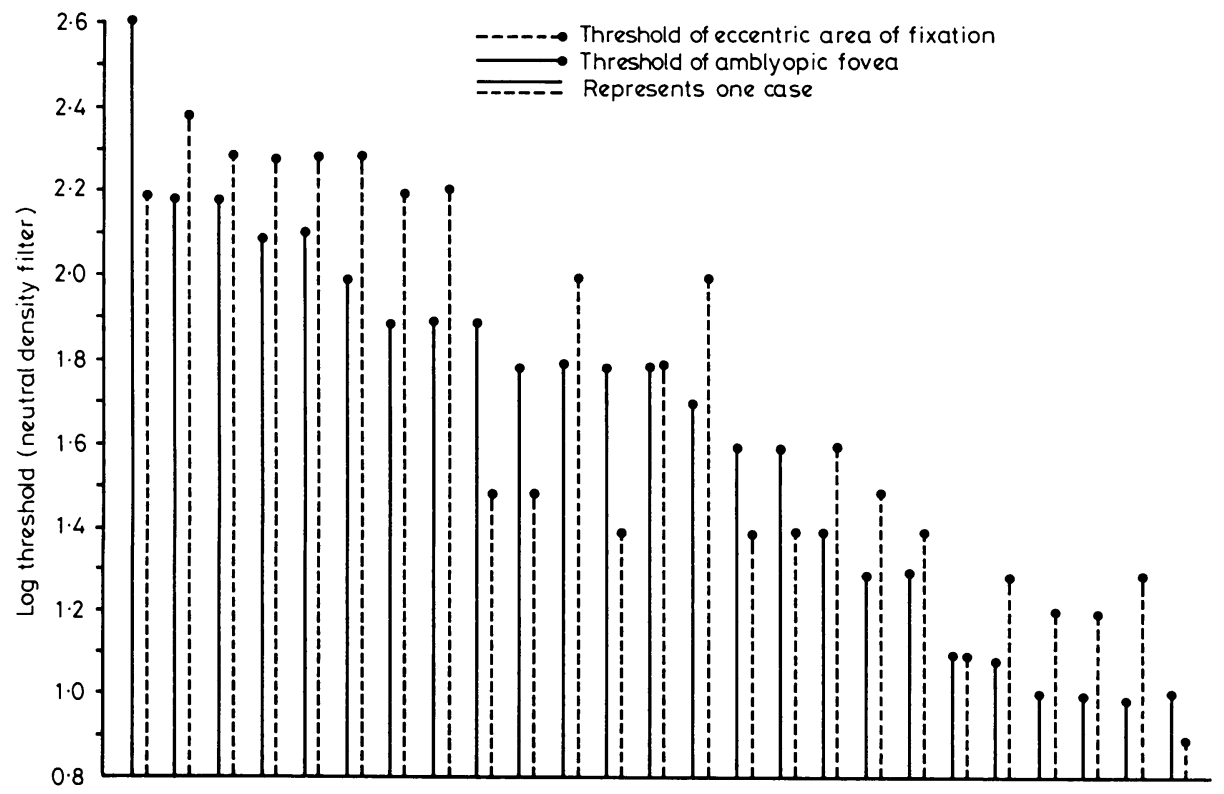

Fig. 4 Relation between sensitivity of eccentric area of fixation and fovea of amblyopia eye. 
under monocular testing. An increase of differential light threshold in all the retinal points tested at $25^{\circ}$ from the centre was also reported by these authors.

In the present study a relative scotoma of $3-4^{\circ}$ could be detected in only 3 out of 25 cases of amblyopia with paramacular fixation by means of monocular kinetic perimetry, while no scotoma was found by kinetic perimetry in 25 cases of amblyopia with foveal fixation.

The following conclusions are drawn from our study: (1) Routine kinetic perimetry has no role in field charting of amblyopic patients in cases of central fixation. (2) Static perimetry is a better technique for field charting in amblyopic patients. (3) The observation that the eccentric point of fixation lay on the edge of the scotoma, and the sensitivity of eccentric area chosen for fixation by the amblyopic eye was superior to the point of foveal fixation in the same eye, provides a better understanding of the role of suppression scotomata in the aetiology of eccentric fixation as proposed by von Noorden. ${ }^{6}$

\section{References}

1 Cuppers $C$. Contribution à la thérapeutique de l'amblyopie. Ann Therap Clin Ophtal 1959; 8: 243-53.

2 Francois J, Verriest G, Verluyten P. Comparison of the results of static and kinetic perimetry in the central region of the visual field of the amblyopic eye. International Strabismus Symposium. Basle: 1966.

3 Mackensen G. Monokulare und binokulare statische perimetrie zur untersuchung der Hammungsvorgange beim schielen. Albrecht von Graefes Arch Klin Ophthalmol 1959; 160: 573-87.

4 Blatt N, Regenbogen L. Le problème de la fixation eccentrique dans l'amblyopie strabique. Arch Ophtalmol (Paris) 1966; 26: 113.

5 Pasino L, Maraini G. Le champ visuel central en vision monoculare dans l'amblyopie. Ann Oculistique 1963; 196: 563.

6 von Noorden G K. Etiology and pathogenesis of fixation anomalies in strabismus. IV Role of suppression scotoma and of motor factors. Am J Ophthalmol 1970; 69: 236-44. 